\title{
Insuficiencia cardíaca aguda
}

\author{
Dr. Sergio Burguez
}

\section{Resumen}

La insuficiencia cardíaca aguda continúa siendo causa frecuente de hospitalización y su morbimortalidad no ha podido ser reducida más allá de los esfuerzos realizados, de ahí la importancia de analizar todo lo referente a su manejo clínico. En este capítulo se aborda la práctica clínica, con detallado análisis de los aspectos diagnósticos y terapéuticos. Para una mayor comprensión del tema se examinan diferentes definiciones y clasificaciones de insuficiencia cardíaca aguda.

Se propone un abordaje conceptual similar al del síndrome coronario agudo en el sentido de mejorar los tiempos de intervención terapéutica y se recomienda la aplicación de un esquema sencillo de evaluación clínica del paciente en base a la presencia o no de signos y síntomas de bajo gasto y congestión.

Al final del capítulo se resumen los principales conceptos que el médico debe considerar frente a este cuadro clínico.

Palabras clave: $\quad$ INSUFICIENCIA CARDÍACA AGUDA REVISIÓN

\section{Acute heart failure}

\section{Summary}

Acute heart failure continues to be a frequent cause of hospitalization and its morbidity and mortality have not been reduced beyond the efforts made, hence the importance to analyze everything related to its clinical management.

This chapter addresses the acute heart failure clinical practice, with detailed analysis of diagnostic and therapeutic aspects.

For a better understanding of the topic, different definitions and classifications of acute heart failure are analyzed. A conceptual approach similar to that of acute coronary syndrome is proposed in the sense of improving the times of therapeutic intervention. Application of a simple scheme for clinical evaluation is recommended, based on the presence or absence of signs and symptoms of low output and congestion.

At the end of the chapter, the most important concepts that should be taken into account by physicians are summarized.

Key words:

ACUTE HEART FAILURE

REVIEW

\section{Introducción}

El síndrome de insuficiencia cardíaca aguda (ICA) es una entidad con alta prevalencia y es la causa de hospitalización más común en pacientes añosos. Tiene pobre pronóstico con alta mortalidad hospitalaria que alcanza 30\%-40\% al año. Es responsable de internaciones prolongadas y de una alta tasa de reingreso hospitalario ${ }^{(1)}$.

En los últimos años se han generado cambios marcados en su enfoque diagnóstico y encare terapéutico.
La recomendación actual es utilizar un abordaje conceptual similar al del síndrome coronario agudo (SCA) aplicando la máxima de "cuanto más pronto mejor", dado que "el tiempo es músculo".

La ICA requiere un diagnóstico y tratamiento urgentes y apropiados. El tratamiento debe ser integral procurando evitar o minimizar el daño orgánico múltiple que se desarrolla en el síndrome, ensombreciendo el pronóstico ${ }^{(2)}$.

Se tiende a realizar un manejo sustentado en los parámetros clínicos clásicos y en varios marcadores

Centro Cardiológico Americano. Montevideo, Uruguay.

Correspondencia: Dr. Sergio Burguez. Correo electrónico: dacomeca@gmail.com

Recibido Set 27, 2017; aceptado Nov 8, 2017 


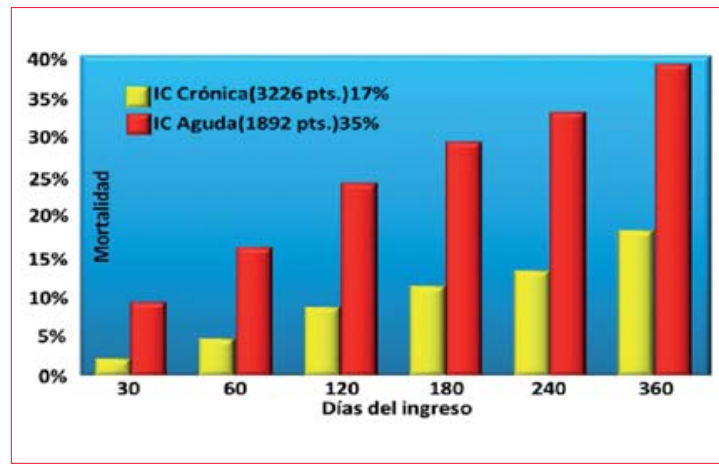

Figura 1. Mortalidad comparativa dentro de los 360 días de la ICA e ICC, modificado del estudio European Society of Cardiology Heart Failure ${ }^{(5)}$.

biológicos de manera de detectar precozmente la disfunción de órgano blanco y el daño miocárdico ${ }^{(3)}$.

Esto permitiría tener valores objetivo a controlar y variables a identificar, que guíen la terapéutica y determinen el pronóstico. Para ello se debe estimular un abordaje multidisciplinario (Heart team) que mejore los resultados y permita manejar adecuadamente los diversos aspectos que poseen estos pacientes.

Dentro de la evidencia actual se destacan las guías de la Sociedad Europea de Cardiología (ESC) sobre Insuficiencia Cardíaca (IC), además de múltiples trabajos que refieren a esta afección ${ }^{(4)}$.

A pesar de ello y a diferencia de lo ocurrido en la IC crónica (ICC), en el caso de la ICA no se han logrado muchos avances en los últimos años en lo que a medidas terapéuticas se refiere.

La mortalidad intrahospitalaria y al año son elevadas, el doble que la de la ICC (figura 1) ${ }^{(5)}$.

\section{Definiciones}

\subsection{Definición de insuficiencia cardíaca}

Se trata de un síndrome clínico caracterizado por síntomas típicos (disnea, edema maleolar y fatiga) que pueden estar acompañados por signos (presión venosa yugular elevada, estertores pulmonares y edema periférico), causado por una anomalía estructural o funcional del corazón, o ambas, resultante en un gasto cardíaco reducido y/o en elevación de las presiones de llenado intracardíacas tanto en reposo como en ejercicio o estrés.

\subsection{Definición de insuficiencia cardíaca aguda}

El International Working Group on Acute Heart Failure Syndromes (WGAHFS) propuso la siguiente definición: "Los síndromes de ICA son definidos como el cambio gradual o rápido de signos y síntomas de IC que resultan en la necesidad de trata-

\begin{tabular}{ll}
\hline \multicolumn{1}{c}{ Tabintomas típicos } & \multicolumn{1}{c|}{ Signos específicos } \\
\hline Disnea & $\begin{array}{l}\text { Presión venosa yugular } \\
\text { aumentada }\end{array}$ \\
Ortopnea & Reflujo hepatoyugular \\
$\begin{array}{l}\text { Disnea paroxística } \\
\text { nocturna }\end{array}$ & Ritmo de galope (R3) \\
$\begin{array}{l}\text { Reducción de la } \\
\text { tolerancia al ejercicio }\end{array}$ & $\begin{array}{l}\text { Impulso apical } \\
\text { desplazado lateralmente }\end{array}$ \\
$\begin{array}{l}\text { Fatiga, cansancio, } \\
\text { aumento del tiempo de } \\
\text { recuperación posejercicio }\end{array}$ & Soplo cardíaco \\
\begin{tabular}{l} 
Edema de tobillos \\
\hline
\end{tabular} \\
\hline
\end{tabular}

miento urgente". Estos son primariamente resultado de congestión pulmonar severa debida a elevadas presiones de llenado (con o sin disminución del volumen minuto [VM]). Pueden presentarse en pacientes con fracción de eyección del ventrículo izquierdo (FEVI) preservada o reducida. Generalmente coexisten patologías tales como enfermedad coronaria, hipertensión arterial (HTA), valvulopatías, arritmias auriculares o enfermedades de otros órganos (incluyendo disfunción renal, anemia y diabetes), que pueden precipitar el síndrome o contribuir a su fisiopatología.

Es una condición de riesgo vital que requiere atención médica inmediata y usualmente lleva a ingreso hospitalario urgente ${ }^{(6,7)}$.

\section{Síntomas y signos}

Los síntomas y signos de ICA se dividen en típicos y más específicos o en menos típicos y menos específicos respectivamente ${ }^{(7)}$ (tablas 1 y 2 ).

La primera aproximación al diagnóstico de ICA consiste en descartar causas alternativas a los síntomas y signos del paciente (infección, embolia pulmonar, anemia severa, insuficiencia renal aguda, enfermedad pulmonar obstructiva crónica [EPOC], etcétera), remarcando que dichas entidades pueden coexistir y ser causa de descompensación para la ICA como se verá más adelante.

Los síntomas y signos típicos de ICA reflejan sobrecarga de líquidos (congestión pulmonar o edemas periféricos, o ambos) o, menos a menudo, gasto cardíaco reducido con hipoperfusión periférica.

Como la sensibilidad y especificidad de los mismos no es buena, una cuidadosa evaluación clínica necesita ser apoyada por estudios complementarios que luego detallaremos. 


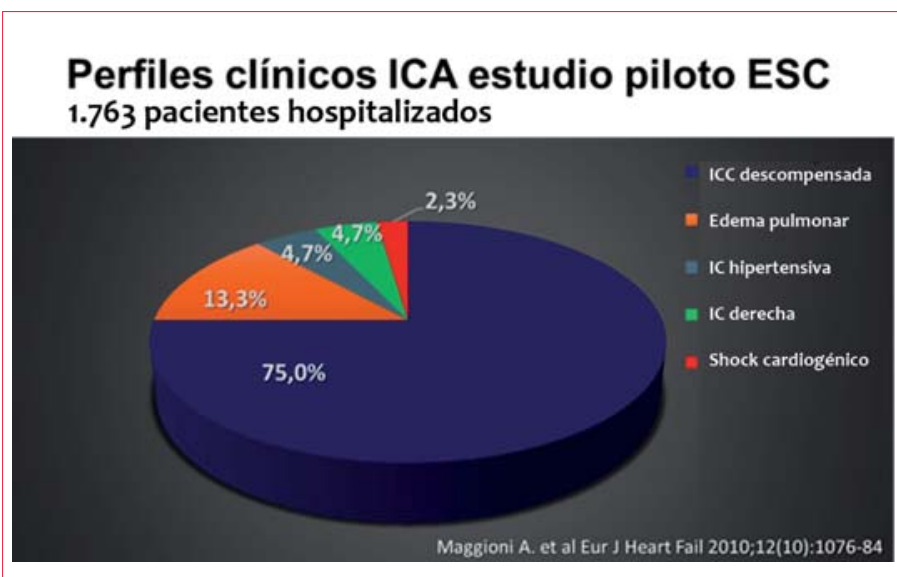

Figura 2. Esquema representativo de las variedades de insuficiencia cardíaca aguda y su prevalencia en el estudio piloto del registro europeo. ICA: insuficiencia cardíaca aguda; ICC: insuficiencia cardíaca crónica; ESC: Sociedad Europea de Cardiología, por su sigla en inglés.

\section{Clasificación}

Existen varias formas de abordar la clasificación de la ICA.

\subsection{Clasificación según la entidad clínica}

Es la más clásica, manejada por el WGAHFS y por las guías 2016 de la ESC; está supeditada a que la ICA refleje una patología cardiovascular (CV) nueva, no presente ni conocida previamente, que debuta agudamente o, por el contrario, se vincule a la descompensación de una patología CV crónica previa conocida o $\mathrm{no}^{(4,6,8,8)}$.

Todas coinciden en distinguir tres entidades clínicas:

- IC "de novo".

- Agudización de una IC previa.

- IC avanzada.

a) Insuficiencia cardíaca "de novo". Es el debut de la IC, con instalación rápida de signos y síntomas. Hasta 25\% de pacientes con ICA no tienen historia previa de IC. La misma puede ser producto de una disfunción sistólica en el contexto de un infarto agudo de miocardio (IAM), o una disfunción diastólica como en una crisis hipertensiva con un ventrículo izquierdo (VI) no complaciente.

Se produce un importante predominio del sistema nervioso simpático (SNS) con aumento de las resistencias vasculares sistémicas y redistribución del flujo pulmonar, no existiendo mecanismos de adaptación previos.

b) Agudización de una insuficiencia cardíaca previa. La mayoría de los casos de ICA (75\% aproximadamente) surge como consecuencia del empeo-
Tabla 2. Síntomas menos típicos y signos menos específicos de IC.

\begin{tabular}{|c|c|}
\hline Sintomas menos típicos & Signos menos especificos \\
\hline Tos nocturna & $\begin{array}{l}\text { Edema periférico (tobillo, } \\
\text { sacro, escroto) }\end{array}$ \\
\hline Sibilancias & Crepitantes pulmonares \\
\hline $\begin{array}{l}\text { Aumento de peso ( }>2 \\
\mathrm{~kg} / \mathrm{sem} \text { ) }\end{array}$ & $\begin{array}{l}\text { Síndrome en menos } \\
\text { torácico (derrame } \\
\text { pleural) }\end{array}$ \\
\hline $\begin{array}{l}\text { Pérdida de peso (en IC } \\
\text { avanzada) }\end{array}$ & Taquicardia \\
\hline Sensación de hinchazón & Polipnea (>16 rpm) \\
\hline Pérdida de apetito & Hepatomegalia \\
\hline Confusión (añosos) & Ascitis \\
\hline Depresión & Caquexia \\
\hline \multicolumn{2}{|l|}{ Palpitaciones } \\
\hline Síncope & \\
\hline
\end{tabular}

ramiento de una IC ya diagnosticada, sea con FEVI reducida (ICFEr) o preservada (ICFEp). Si bien puede haber progresión rápida de síntomas y signos, generalmente pueden reconocerse uno o más factores de descompensación y se ponen en funcionamiento mecanismos de adaptación (SNS, sistema renina angiotensina aldosterona [SRAA], drenaje linfático pulmonar).

c) Insuficiencia cardíaca avanzada. Se presenta habitualmente como refractaria al tratamiento con estado de bajo volumen sistólico. Se observa en aproximadamente 5\% de los pacientes con ICA y puede variar desde edema pulmonar y bajo gasto cardíaco hasta shock cardiogénico (SC) ${ }^{(7)}$.

\subsection{Clasificación según el perfil clínico}

Los pacientes pueden presentarse con un amplio espectro de trastornos que van desde el edema agudo de pulmón con o sin SC, lo que implica alto riesgo vital, hasta una enfermedad menos grave caracterizada por empeoramiento del edema periférico. Asimismo, el tiempo de instalación puede variar notoriamente; muchos pacientes describen un período de deterioro de días o incluso semanas previas y otros sufren IC en cuestión de horas o minutos (por ejemplo, IAM).

Muchos pacientes se presentan con presión arterial (PA) normal o alta y síntomas o signos de congestión pulmonar o sistémica más que de bajo gasto cardíaco. 


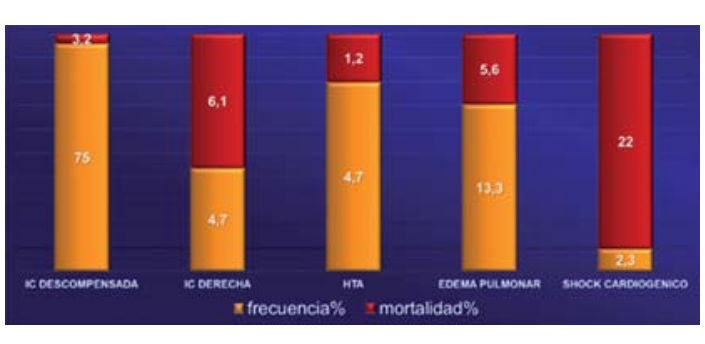

Figura 3. Perfiles clínicos de IC en pacientes internados: frecuencia y mortalidad.

En forma esquemática los perfiles clínicos de la ICA son: a) IC descompensada; b) edema pulmonar; c) IC hipertensiva; d) IC derecha; e) SC.

En la figura 2 se esquematiza que la ICC descompensada es el grupo dominante siendo cercano al 75\% del total y, por su parte, el SC, la forma más grave, constituye un pequeño porcentaje de aproximadamente $2,3 \%(5)$

La clasificación de la ICA según el "perfil clínico" constituye un aspecto relevante, pues está directamente ligada al pronóstico. Si bien la mortalidad "global" de la IC hospitalizada ronda 3,8\%, esta varía significativamente según el perfil clínico a que pertenezca. Así la mortalidad puede ser tan baja como el 1,2\% para la IC hipertensiva, pero de hasta $22 \%$ para el SC (5) (figura 3 ).

La descompensación de una ICC previa posee la más alta prevalencia del grupo $(75 \%)$, pero una mortalidad baja de $3,2 \%$.

\subsection{Clasificación según el estado hemodinámico}

La clasificación clínica según el estado hemodinámico se basa en la clasificación de Forrester diseñada para el IAM con sus cuatro grupos de presentación. Dicha clasificación requiere el monitoreo hemodinámico con catéter de Swan Ganz para determinar el gasto cardíaco y la presión capilar pulmonar, resultando cuatro patrones hemodinámicos con diferente manejo clínico y farmacológico. Es muy útil desde el punto de vista pronóstico ${ }^{(9)}$.

La clasificación actual, que introducen las guías, es muy práctica pues no requiere intervencionismo para monitoreo y se basa simplemente en el examen del paciente dirigido a detectar la presencia (húmedo) o la ausencia (seco) de síntomas o signos de congestión y la presencia (frío) o la ausencia (caliente) de signos de hipoperfusión periférica.

La combinación de estas opciones identifica, al igual que la clasificación de Forrester, cuatro grupos de pacientes:

a) Caliente y húmedo (bien perfundido y congestivo), el patrón más frecuente. b) Frío y húmedo (hipoperfundido y congestivo).

c) Frío y seco (hipoperfundido sin congestión).

d) Caliente y seco (compensado, bien perfundido sin congestión).

Esta clasificación es útil para guiar la terapéutica en la fase inicial y además proporciona valiosa información pronóstica(4,10) (figura 4).

\subsection{Clasificación según el patrón de presión arterial}

Una manera sencilla de agrupar los pacientes con ICA es según la presión arterial (PA) al momento del ingreso hospitalario.

Un grupo importante de ICA debuta con PA normal (PAS $<140 \mathrm{mmHg}$ ) o elevada ( $\mathrm{PAS} \geq 140$ $\mathrm{mmHg}$ ).

Los pacientes graves, con disnea significativa y PA elevada (ICA hipertensiva) parecen tener el mayor riesgo de eventos adversos en lo inmediato, pero una vez controlados el riesgo a 30-60 días disminuye. Los pacientes con PA normal a menudo se presentan con síntomas menos severos.

Un pequeño grupo del total (5\%-8\%) debuta con cifras de $\mathrm{PAS} \leq 90 \mathrm{mmHg}$ (ICA hipotensiva), lo que ensombrece el pronóstico sobre todo si existen signos de hipoperfusión o bajo gasto como oligu$\mathrm{ria}^{(11,12)}$.

\section{Etiología}

No hay una única tipificación etiológica de ICA y existe superposición entre las diferentes causas. Pueden coexistir patologías diferentes, de origen CV y no CV, que coparticipan en la etiología. La identificación de estas patologías debe ser parte de la valoración diagnóstica en tanto muchas de ellas requieren un manejo terapéutico específico.

Los pacientes con IC y cardiopatía isquémica tienen historia de IAM, angina o revascularización miocárdica previa. A pesar de esto un angiograma normal no excluye la cicatriz miocárdica (valorada con cardiorresonancia) o una alteración de la microcirculación coronaria como explicación alternativa a la evidencia de isquemia miocárdica ${ }^{(4)}$.

Como fue mencionado, $75 \%$ de las ICA surgen de la descompensación de una cardiopatía crónica. En este grupo, la tarea diagnóstica se simplifica pues la cardiopatía ya es conocida y solo se requiere identificar la causa de descompensación.

En el 25\% en que la ICA surge "de novo", la cardiopatía no es conocida y el equipo asistencial debe hacer los esfuerzos necesarios para identificarla utilizando todas las herramientas a su alcance. Esto es crucial a la hora de abordar el síndrome, ya que 


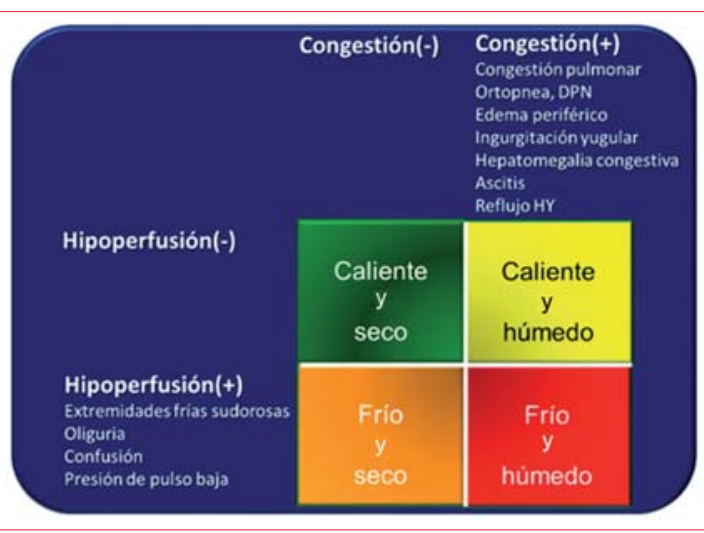

Figura 4. Evaluación clínica del perfil hemodinámico de la ICA.

muchas de las etiologías requieren tratamientos específicos que exceden al tratamiento fisiopatológico utilizado en la ICA (revascularización en los SCA, cirugía en las insuficiencias valvulares agudas o en la estenosis aórtica severa, tratamiento del hiper o hipotiroidismo en la enfermedad tiroidea severa).

El acrónimo CHAMP recuerda las principales etiologías asociadas con $\mathrm{ICA}^{(4)}$ :

- C: síndromes coronarios agudos.

- H: hipertensión.

- A: arritmias.

- M: complicaciones mecánicas agudas.

- P: embolismo pulmonar.

Las principales etiologías de ICA se resumen en la siguiente lista:

- Enfermedades del miocardio.

- Cardiopatía isquémica.

- Daño tóxico.

- Daño inmuno-mediado.

- Daño inflamatorio.

- Infiltración.

- Alteraciones metabólicas.

- Anomalías genéticas.

- Condiciones de carga anormales.

- Hipertensión.

- Defectos valvulares.

- Defectos miocárdicos estructurales.

- Anomalías pericárdicas y endomiocárdicas.

- Estados de alto gasto cardíaco.

- Sobrecarga de volumen.

- Arritmias.

- Taquiarritmias.

- Bradiarritmias.

\subsection{Insuficiencia cardíaca aguda y enfermedad coronaria}

La coronariopatía es la etiología más frecuente de la IC, con una prevalencia de 50\%-65\%, y puede ser causa tanto de ICFEr como de ICFEp. Los pacientes pueden presentarse con SCA complicados con ICA o más comúnmente con ICA y coronariopatía crónica subyacente. Se trata de una etiología "potencialmente tratable", con valor pronóstico adverso a largo plazo, sinérgico e independiente.

Un reciente estudio retrospectivo de cohorte usó las bases de datos del Truven Health Market Scan Commercial y de Medicare, entre 2010-2013, para evaluar la utilización de estudios invasivos y no invasivos en el diagnóstico de coronariopatía realizados durante la hospitalización y hasta los 90 días del ingreso de pacientes con diagnóstico de IC "de novo"(13).

De 67.161 pacientes únicamente el $17 \%$ se sometió a un test para detectar cardiopatía isquémica al ingreso y esto aumentó a $27 \%$ a 90 días del alta; $2 \%$ se revascularizó durante la hospitalización y a 90 días la tasa de revascularización se incrementó escasamente a $4 \%$. Los tests de isquemia (ecoestrés o medicina nuclear) se realizaron en 7,9\% durante el ingreso hospitalario aumentando a $14,6 \%$ a 90 días. La coronariografía se realizó en $11 \%$ de los pacientes durante la hospitalización y en $16 \%$ a los 90 días.

Por tanto, puede concluirse que una pequeña parte de los pacientes con ICA son sometidos a detección de isquemia o coronariografía, lo cual indica una subutilización de dichos estudios en esta población con alta prevalencia de enfermedad coronaria.

\subsection{Diagnóstico de infarto agudo de miocardio acompañante}

El IAM debe comprometer una gran extensión de miocardio (masa crítica) para causar ICA, excepto en situaciones de arritmia o insuficiencia mitral aguda en las que infartos pequeños pueden debutar con ICA.

Como regla general, en ausencia de cambios del electrocardiograma (ECG) que sean indicadores de una gran área de isquemia (elevación del ST, nuevo bloqueo completo de rama izquierda, elevación del ST en aVR, o depresión de ST en múltiples derivaciones precordiales), los pacientes con diagnóstico clínico de ICA no requieren realizar una coronariografía "temprana"(14).

La coronariografía y una eventual revascularización están indicadas "luego" de la estabilización de la ICA.

\section{Factores precipitantes}

En general se reconocen uno o más factores precipitantes de la ICA, y su identificación es relevante para la terapéutica, que puede ir desde la administración de antibióticos para tratar una neumonía, has- 


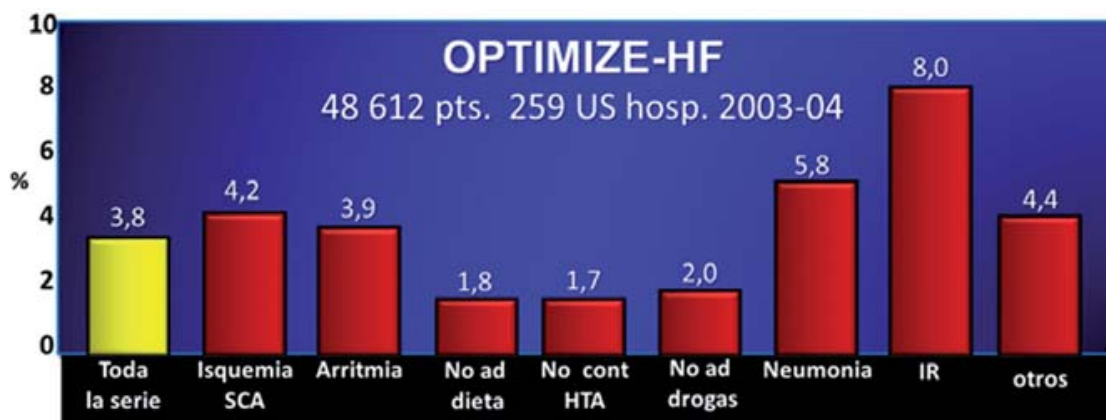

Figura 5. Efecto sobre la mortalidad hospitalaria (no ajustada) de los diferentes "gatillos" en la presentación de ICA del registro Optimize-HF. Se muestra en la columna amarilla la mortalidad de toda la serie y en rojo la mortalidad en relación con los factores de descompensación de la ICA considerados de forma individual

SCA: síndrome coronario agudo; IR: insuficiencia renal; No ad: no adherencia

ta la corrección de una taqui o bradiarritmia con antiarrítmicos, cardioversión eléctrica (CVE) o implante de marcapaso.

Los factores precipitantes difieren en su frecuencia según se trate de IC "de novo" o descompensación de una ICC. Para la ICA "de novo" los SCA, la enfermedad valvular y las arritmias son los factores precipitantes más frecuentes, mientras que para la ICC descompensada la no adherencia al tratamiento es el factor más frecuente ${ }^{(15)}$.

En el estudio OPTIMIZE-HF la neumonía, los cuadros respiratorios, la isquemia y las arritmias fueron identificados como los precipitantes más comunes con una mortalidad global de la ICA de $3,8 \%$, que varía francamente si se analiza en relación con el factor desencadenante. Así se observa una alta mortalidad en la falla renal (8\%), mientras que es muy baja (1,8\%-2\%) en el abandono de la dieta o del tratamiento farmacológico, siendo estos casos los que presentan mejor pronóstico(16) (figura 5).

Cuando se realiza un análisis multivariado del valor pronóstico de los factores precipitantes a 30-90 días posalta, la isquemia con o sin SCA y la insuficiencia renal tienen un peso negativo significativo sobre la mortalidad, mientras que la HTA no controlada presenta menos riesgo de muerte y de reingreso hospitalario ${ }^{(12)}$.

\section{Diagnóstico}

El síntoma clave de ICA es la disnea aguda, pero existe un amplio espectro de patologías que también se presentan con disnea, como la neumonía, el EPOC descompensado y la embolia pulmonar.

$\mathrm{Si}$ a esto sumamos el hecho de que los pacientes pueden tener más de una patología que complica la correcta interpretación del cuadro, estamos frente a un síndrome que hace desafiante la posibilidad del diagnóstico temprano.
El retardo en el diagnóstico y tratamiento correctos puede influir tanto en la estadía hospitalaria como en la morbilidad y mortalidad.

El proceso diagnóstico incluye tres etapas ${ }^{(14)}$ :

a) Asegurar que la ICA es la causa de la disnea. Esta etapa se basa en el juicio clínico de integrar la historia y examen físico con los estudios complementarios, incluyendo radiografía de tórax (RxTx), ECG y evaluación de los péptidos natriuréticos (PN).

b) Definir la anomalía cardíaca subyacente. Se basa en la realización de diagnóstico de imagen cardíaca mediante el ecocardiograma transtorácico (ETT). Si los PN están disponibles y la hemodinamia es estable (ausencia de shock), la realización del ETT puede diferirse hasta el segundo día.

c) Identificar los precipitantes de la ICA. También se inicia en la emergencia y se orienta a identificar los gatillos de la ICA para ofrecer la terapéutica específica además del tratamiento básico de la IC.

\subsection{Estudios complementarios}

\subsubsection{Ecocardiograma}

Es el examen paraclínico más útil y disponible para establecer el diagnóstico en los pacientes con sospecha de IC. Provee información estructural y funcional del corazón no proporcionada en forma tan accesible y económica por ninguna otra técnica diagnóstica.

Informa sobre dimensiones y volúmenes cavitarios, grosor parietal, función ventricular sistólica y diastólica, anatomía y función valvulares, permitiendo calcular la presión pulmonar, el gasto cardíaco, la presión arterial media (PAM) y la presión venosa central (PVC), así como las resistencias vasculares sistémicas y pulmonares, aportando informa- 
ción de la volemia a través del diámetro de la vena cava inferior y su variación respiratoria.

La realización "inmediata" de un ETT es mandatoria en pacientes con inestabilidad hemodinámica (SC) y con sospecha de anomalías funcionales o estructurales agudas de riesgo vital (por ejemplo, complicaciones mecánicas del IAM, insuficiencias valvulares agudas, disección aórtica, etcétera). La máxima “cuanto más grave el paciente, más rápido debe valorarse con ETT", debe recordarse y cumplirse. También debe considerarse en todos los pacientes con ICA “de novo" y en aquellos cuya función ventricular se desconoce.

No se ha establecido un plazo óptimo para su realización, aunque debería ser, preferentemente, dentro de las 48 horas posteriores al ingreso.

El ETT es equivalente a las técnicas hemodinámicas invasivas (cateterismo) para guiar la terapéutica y mejorar el pronóstico, pero sin los riesgos y costos de este último(17).

Dada la falta de especificidad de los síntomas de IC y la coexistencia de comorbilidades y cambios relacionados con la edad que comparten los mismos síntomas es necesario evaluar la función sistólica y diastólica mediante el ETT.

Este permite categorizar los pacientes con ICA en grupos según la FEVI: preservada o reducida y más recientemente el grupo de FEVI de rango medio $^{(4)}$.

Cabe destacar que hasta 50\% de los ingresos por ICA pueden tener FEVI preservada. Por tanto, una FEVI preservada no descarta el síndrome de ICA, sino que debe orientar hacia etiologías asociadas como la ICA hipertensiva, la disfunción valvular aguda, las taquiarritmias como la fibrilación auricular (FA) aguda rápida, entre otras.

Si bien la tasa de mortalidad hospitalaria es algo más baja en la ICFEp respecto a la ICFEr, la duración de la estadía hospitalaria y las tasas de reingreso son similares ${ }^{(4)}$.

Por otra parte, la disfunción diastólica puede progresar a disfunción sistólica.

Los parámetros asociados a una ICFEr son: a) VI dilatado (por diámetros y/o volúmenes de fin de diástole y fin de sístole); b) motilidad parietal anormal; c) FEVI disminuida; d) flujo transvalvular aórtico disminuido (VTI bajo); e) regurgitaciones valvulares mitrales y tricuspídeas de carácter funcional; f) hipertensión pulmonar; g) signos Doppler indicadores de aumento en las presiones de llenado del VI ${ }^{(17)}$

En el caso de la ICFEp el diagnóstico es más complejo y se basa en el hallazgo de alteraciones en la señal Doppler del llenado ventricular, aumento de la masa ventricular o auriculomegalia izquierda, o ambas.

\subsubsection{Paraclínica biológica básica}

Existe acuerdo entre los diferentes autores sobre la batería de estudios biológicos básicos a solicitar a todo paciente con $\mathrm{IC}^{(4)}$.

Los mismos están dirigidos a descartar complicaciones como la anemia y el déficit de hierro, comorbilidades como la diabetes y dislipemia, enfermedad tiroidea, disfunciones de órgano blanco como la falla renal o hepática, disionías, así como la liberación de marcadores de estiramiento miocárdico como los PN (tabla 3 ).

\subsubsection{Péptidos natriuréticos}

La determinación de biomarcadores ha impactado dramáticamente en la forma de evaluación y manejo de los pacientes con IC. Los PN tipo B (BNP) y $\mathrm{N}$-terminal proBNP (NT-proBNP) son marcadores que ayudan a determinar el diagnóstico y pronóstico en la IC y algunos estudios sobre tratamiento guiado por péptidos parecen promisorios, ya que se correlacionan con la clase funcional y son mejores estratificadores de riesgo que la FEVI ${ }^{(18,19)}$.

Los PN tienen utilidad en la emergencia cuando existen dudas sobre el origen cardiológico de la disnea.

El diagnóstico en pacientes añosos con insuficiencia respiratoria es inadecuado hasta en $20 \%$ de los casos. Estos diagnósticos erróneos se asocian a un aumento significativo de la mortalidad, mostrando la necesidad de contar con herramientas de alta sensibilidad y especificidad, rápidamente accesibles. El potencial de los PN para aumentar el juicio clínico se ha identificado en varios estudios ${ }^{(20,21)}$.

En el estudio REDHOT, los médicos eran ciegos a los niveles de BNP al tomar la decisión de ingresar a los pacientes. Los niveles de BNP fueron mayores en aquellos pacientes dados de alta y fueron más del doble en los pacientes que murieron a 30 días respecto a los supervivientes. Este patrón se mantuvo a 90 días, indicando que el BNP podría haber sido útil al decidir si el paciente debería haber ingresado o no ${ }^{(22)}$.

En un análisis del registro US Acute Decompensated Heart Failure National Registry (ADHERE) las determinaciones rápidas de $\mathrm{BNP}$ estuvieron asociadas con inicio más rápido del tratamiento diurético y con una modesta mejoría en la mortali$\operatorname{dad}^{(23)}$.

El valor predictivo negativo es alto tanto en el entorno agudo como no agudo (0,94-0,98), mientras que el valor predictivo positivo es más bajo en ambos entornos $(0,66-0,67)$. Por tanto, se recomienda 
Tabla 3. Paraclínica básica bioquímica recomendada para realizar en todos los pacientes con IC y nivel de evidencia correspondiente.

\begin{tabular}{l|l}
\hline Recomendación & \multicolumn{1}{c}{ Clase } \\
\hline Hemoglobina, recuento leucocitos & \\
Sodio, potasio & I \\
Creatinina, clearance de creatinina, azoemia & \\
Hepatograma, GOT, GPT, GGT & \\
\hline Glucosa, HbA1c & \\
\hline Perfil lipídico & \\
\hline TSH & \\
\hline Ferritina, índice saturación de transferrina & IIa guías ESC \\
\hline Péptidos natriuréticos & IIb guías AHA \\
\hline $\begin{array}{l}\text { GOT: transaminasa glutámico-oxalacética; GPT: transaminasa glutámico-pirúvica; GGT: gamma glutamil transferasa; HbA1c: he- } \\
\text { moglobina glucosilada;TSH: hormona tirotrófica; ESC: Sociedad Europea de Cardiología; AHA: Asociación Americana del Corazón. }\end{array}$ \\
\hline
\end{tabular}

usar los PN para "descartar" pero no para "establecer" el diagnóstico, ya que niveles elevados no confirman automáticamente el diagnóstico de $\mathrm{IC}^{(4)}$.

La concentración de PN es útil como test diagnóstico inicial sobre todo cuando el ETT no está disponible rápidamente. Pacientes con valores bajos no necesitan realizarse un $\mathrm{ETT}^{(4)}$.

Cuando los valores son normales es improbable que exista IC y se debe buscar otra explicación para los síntomas.

En la presentación en la emergencia o UCI, por tanto, el nivel de PN (BNP, NT pro-BNP) debería medirse en todos los pacientes con disnea de inicio agudo y sospecha de ICA para ayudar a la diferenciación de causas no cardíacas de disnea(24).

El límite superior de lo normal para los $\mathrm{PN}$ en los escenarios agudos es mayor (BNP: $100 \mathrm{pg} / \mathrm{ml}$ NT pro-BNP: $300 \mathrm{pg} / \mathrm{ml}$ ) que en los escenarios no agudos (BNP: $35 \mathrm{pg} / \mathrm{ml}$; NT pro-BNP: $125 \mathrm{pg} / \mathrm{ml}$ ). Los PN tienen similar valor diagnóstico en la ICFEr e ICFEp, pero en promedio los valores son más bajos en la ICFEp ${ }^{(4)}$.

Varias causas cardíacas y extracardíacas elevan los PN, lo cual debilita su utilidad diagnóstica, entre ellas la edad y la disfunción renal. Asimismo, pueden detectarse niveles bajos de PN en algunos pacientes con IC descompensada en estadio final, o con edema pulmonar flash e ICA derecha y en pacientes obesos.

No existen parámetros clínicos objetivos que indiquen cuándo se ha logrado el tratamiento suficiente que permita el alta hospitalaria segura y con baja tasa de reingresos. Estudios iniciales deposita- ron su esperanza en la medición de los $\mathrm{PN}$ con este objetivo, obteniéndose resultados variables.

El no descenso o el aumento de BNP, o ambos, luego del inicio de la terapéutica es un signo de peor pronóstico que puede indicar la necesidad de medidas terapéuticas adicionales (por ejemplo, vasodilatadores). Por su parte, el descenso intrahospitalario de BNP puede ayudar a determinar la "euvolemia" del paciente y parece ser que cuanto más bajo el nivel de PN al alta, mejor estará el paciente.

Aún no existe suficiente información que permita correlacionar un bajo nivel de PN con disminución de reingresos por IC.

Como corolario de lo dicho acerca de los PN, no deben tomarse conductas basadas simplemente en el valor detectado de los mismos, sino que debe analizarse dicho valor en conjunto con el contexto clínico y paraclínico de los pacientes teniendo especial precaución en pacientes añosos o con ICFEp, en los cuales la evidencia es aún escasa ${ }^{(25,26)}$.

Otros biomarcadores "nuevos" han surgido como promisorios para su medición seriada. Ellos miden diferentes procesos fisiopatológicos asociados al desarrollo y progresión de la IC, como injuria miocárdica, inflamación, y remodelado. Estos incluyen la pro-endotelina-1 C terminal (CT-pro-ET-1), pro-adrenomedulina medio-regional (MR-proADM), y el péptido natriurético pro-atrial medio-regional (MR-proANP), soluble ST2 (sST2), factor de diferenciación de crecimiento (GDF-15) y galectina -3, pero aún esperan su validación en el "mundo real" de la $\mathrm{ICA}^{(26)}$. 


\subsubsection{Marcadores de lesión orgánica}

Se ha implicado al daño multiorgánico y a la congestión persistente durante los primeros días del ingreso hospitalario como contribuyentes al mal pronóstico de la ICA. La disfunción de órgano blanco incluido el daño miocárdico, renal y hepático son predictores independientes de aumento de mortalidad en los pacientes con $\mathrm{ICA}^{(1)}$.

Signos de congestión no resuelta y episodios de empeoramiento de la función cardíaca son también predictores poderosos de pobre pronóstico. La prevención del daño orgánico y la corrección de la congestión pueden estar asociadas con menor mortalidad en la ICA ${ }^{(27)}$.

Una estratificación del riesgo basada en combinación de biomarcadores que reflejen las diversas vías fisiopatológicas de la IC es un abordaje promisorio que podría servir como "marca o patente" de la enfermedad y podría incrementar significativamente la certeza de las predicciones de riesgo.

\section{- 7.1.2.2.1. Troponinas cardíacas}

Como los PN, el nivel de troponinas puede elevarse en la IC crónica o aguda descompensada, sugiriendo injuria o necrosis miocítica, o ambas. Las troponinas se han usado clásicamente como auxiliares para el diagnóstico de los SCA, aunque se elevan también en otras cardiopatías.

La elevación del nivel de troponinas ( $\mathrm{I}$ o T) es fuerte predictor pronóstico, independientemente de la etiología y debe interpretarse de acuerdo al contexto clínico.

Con la llegada de las troponinas altamente sensibles (hsTn) la necrosis miocárdica se detecta ahora en la gran mayoría de los síndromes de IC.

En pacientes con ICA se ha demostrado que las concentraciones de hsTn se encuentran frecuentemente elevadas, sobre todo en los que sufren complicaciones ${ }^{(28)}$.

Actualmente la determinación de troponinas se recomienda para excluir los SCA en pacientes que se presentan con IC agudamente descompensada.

- 7.1.2.2.2. Injuria renal aguda

La falla renal es uno de los más poderosos predictores pronósticos en la IC.

Los pacientes con IC tienen una significativa disminución en su función renal.

El riesgo de muerte en pacientes con reducción de la tasa de filtrado glomerular (TFG) es más del doble que en aquellos sin reducción ${ }^{(29)}$.

El término injuria renal aguda (IRA) se utiliza para referirse al incremento de la creatininemia o reducciones en la TFG que suceden rápidamente y se define en base a los siguientes criterios:
- Incremento de 1,5-1,9 veces de la creatininemia respecto al valor basal 1-7 días antes o durante la hospitalización.

- Incremento $\geq 0,30 \mathrm{mg} / \mathrm{ml}$ de la creatininemia dentro de las 48 horas.

- Gasto urinario 0,5 ml/kg/h por 6-12 horas $^{(29)}$.

Cualquier deterioro de la función renal que no cumpla con estos criterios debe interpretarse como "pseudoinjuria renal aguda" en la que no hay evidencia de riesgo asociado, exceptuados los ascensos muy importantes, como la duplicación de la creatininemia.

El deterioro de la función renal en la IC se denomina síndrome cardiorrenal (SCR) y se define como los desórdenes de corazón y riñón donde una disfunción aguda o crónica en uno de ellos puede inducir disfunción aguda o crónica en el otro y será analizado en otro capítulo de este suplemento. Existen cinco tipos de SCR y el tipo 1 es el asociado con la ICA. Se trata de deterioro "agudo" de la función cardíaca que lleva a injuria o disfunción renal ${ }^{(30)}$.

Entre 27\%-40\% de los pacientes internados con ICA desarrollan IRA, presentando mayor morbimortalidad y estadía hospitalaria más prolongada. Esta interacción cardiorrenal incluye deterioro hemodinámico, con disminución del gasto cardíaco e incremento de la congestión y presión venosa renales que puede llevar a hipertensión intersticial y posiblemente a hipertrofia, fibrosis e injuria tubular, con disminución de la perfusión renal y del TFG.

Existen otras causas para la disminución de la TFG, como depleción de volumen intravascular, deshidratación, diuresis excesiva, medicación que altera el manejo tubular de creatinina y uso de inhibidores del SRAA ${ }^{(31)}$. Estas causas no siempre están relacionadas con pronóstico adverso. Incrementos en la creatinina ocurridos durante la hospitalización y el tratamiento de ICA no siempre son clínicamente relevantes especialmente si se acompañan de una descongestión apropiada, diuresis y hemoconcentración $^{(29)}$.

Un nuevo biomarcador de IRA es la cistatina-C, con valor diagnóstico y pronóstico también validados en la IC. Se trata de un inhibidor de la serinproteasa liberada desde todas las células funcionantes. Su clearance depende enteramente del filtrado glomerular haciéndolo un marcador típico. Aunque la cistatina-C es algo superior a la estimación del filtrado glomerular, su aumento no solo indica disfunción renal, ya que está relacionado también con procesos inflamatorios y con la severidad de la cardiopatía de base ${ }^{(31)}$.

Se correlaciona positivamente con el NT-proBNP en pacientes con ICA e IRA y representa un predictor independiente de mortalidad a un año en ICA. 


\begin{tabular}{|c|c|c|c|}
\hline & $H R$ & IC $95 \%$ & $p$ \\
\hline Congestión pulmonar o sistémica al ingreso & 2,73 & $1,71-4,35$ & $<0,0001$ \\
\hline Uso de inotrópicos & 2,0 & $1,51-2,65$ & $<0,0001$ \\
\hline $\mathrm{Na}<136 \mathrm{mEq}$ versus $\geq 136 \mathrm{mEq}$ al ingreso & 1,84 & $1,45-2,34$ & $<0,0001$ \\
\hline FEVI $<40 \%$ versus $\geq 40 \%$ al ingreso & 1,66 & $1,14-2,44$ & 0,009 \\
\hline Disfunción renal crónica & 1,48 & $1,13-1,95$ & 0,004 \\
\hline Creatinina $<1,5 \mathrm{mg} / \mathrm{dl}$ versus $\geq 1,5 \mathrm{mg} / \mathrm{dl}$ al ingreso & 1,43 & $1,10-1,87$ & 0,007 \\
\hline R3 al ingreso & 1,37 & $1,05-1,80$ & 0,021 \\
\hline Hospitalización previa por IC & 1,31 & $1,03-1,67$ & 0,030 \\
\hline Edad (por año) & 1,03 & $1,02-1,04$ & $<0,0001$ \\
\hline PAS (mmHg) & 0,995 & 0,991-0,999 & 0,028 \\
\hline
\end{tabular}

Na: natremia; FEVI: fracción de eyección del ventrículo izquierdo; R3: tercer ruido cardíaco; IC: insuficiencia cardíaca; PAS: presión arterial sistólica

Además, es un factor independiente de pronóstico en $\mathrm{IC}$ con FEVI $>40 \%$ y en pacientes estables con $\mathrm{ICFE}<35 \%$.

\section{- 7.1.2.2.3. Disfunción hepática}

Los tests de función hepática (TFH) anormales son frecuentes en la ICA y en la ICC y están asociados con pronóstico adverso. El efecto deletéreo de la IC sobre el hígado es multifactorial ${ }^{(32)}$.

A saber:

a) Sobrecarga de volumen y presión.

b) Gasto cardíaco reducido, hipoperfusión hepática e injuria hipóxica.

c) Otros: activación de la cascada inflamatoria, estrés oxidativo, etcétera.

Las guías americanas y europeas de IC recomiendan valorar rutinariamente los $\mathrm{TFH}$ al ingreso hospitalario $^{(4)}$. $\operatorname{tes}^{(33)}$ :

Los patrones anormales de TFH son los siguien-

- Perfil de necrosis hepatocelular (ALT/AST 3 veces el valor superior normal)*.

- Perfil colestásico: bilirrubinas, fosfatasa alcalina (FA) o gamma-glutamil transferasa (GGT) elevadas.

- Perfil mixto (FA, bilirrubinas, GGT y ALT, ambas encima del valor superior normal).

* ALT: alanina transaminasa; AST: aspartato transaminasa
En el estudio EVEREST, diseñado para evaluar la eficacia de tolvaptán (antagonista del receptor de vasopresina 2 ) en pacientes con IC en clase funcional III-IV y FEVI $\leq 40 \%{ }^{(34)}$, se presentaron alteraciones en los TFH desde el inicio de la hospitalización y durante una semana, y a excepción de las bilirrubinas, permanecieron incambiadas a pesar de la mejoría de los síntomas congestivos y del BNP. Todos los TFH mostraron mejoría posalta excepto la FA.

Los niveles basales más bajos de albúmina se observaron en pacientes más añosos, con más comorbilidades no cardíacas, menor FEVI y valores elevados de bilirrubinas. También se asociaron con aumento del riesgo de mortalidad cardiovascular y total, y con mayor reingreso por IC.

Las determinaciones seriadas de TFH tienen más valor predictivo que las aisladas.

\subsubsection{Electrocardiograma}

El ECG generalmente es patológico en la IC, aportando información sobre la etiología. Las arritmias supraventriculares rápidas (FA o flutter) pueden ser causa de descompensación. También puede evidenciar signos de necrosis o isquemia miocárdicas que orienten a la etiología isquémica. Por otra parte, un ECG normal aleja la IC como causa de los síntomas por su alto valor predictivo negativo ${ }^{(4)}$.

\subsubsection{Radiografía de tórax}

La radiografía de tórax es un auxiliar diagnóstico clásico y continúa siendo una de las piedras angulares del diagnóstico. Aporta datos sobre el grado de hipertensión veno-capilar pulmonar, cardiomega- 
lia, hipertensión arterial pulmonar y patología aórtica.

Sus criterios diagnósticos son ampliamente conocidos, por lo que no serán analizados. Por otra parte, colabora en la identificación de diagnósticos diferenciales como neumonía, embolia pulmonar, EPOC, que pueden estar presentes como comorbilidades. Debe recordarse que en el 15\% de los pacientes hay ausencia de signos de congestión, lo cual limita su valor como método de screening.

\section{Predictores de riesgo}

Durante la evaluación del paciente con ICA es importante poder detectar aquellos hechos clínicos o paraclínicos asociados a un mayor riesgo de mortalidad $(14,35)$

La tabla 4 muestra los predictores que Maggioni y colaboradores establecen como fuertemente asociados con mortalidad, ordenados según su significancia estadística ${ }^{(37)}$.

Los datos del registro ADHERE muestran que la azoemia elevada ( $\geq 43 \mathrm{mg} / \mathrm{dl}$ ) es el mejor predictor de mortalidad hospitalaria, seguido por PAS baja $(<115 \mathrm{mmHg})$ y creatininemia elevada $(\geq 2,5$ $\mathrm{mg} / \mathrm{dl})^{(37)}$.

Según este registro los pacientes que ingresan con ICA y requieren de la administración de drogas vasoactivas tienen peor pronóstico e incrementan el riesgo de mortalidad hasta en $12 \%$-13\%(12,23,37,38).

La combinación de elevación de BNP y troponinas I identifica a pacientes con un aumento de 12 veces en el riesgo de morir durante la internación.

En sentido opuesto, si bien no están claramente identificados los marcadores de bajo riesgo para la ICA, hay hechos que, de presentarse, se asocian con bajo riesgo de eventos adversos: a) PAS $\geq 160$ $\mathrm{mmHg}, \mathrm{b})$ troponinas normales ${ }^{(39)}$.

\section{Terapéutica}

Por el riesgo vital mencionado debe iniciarse el tratamiento en el primer contacto médico, ya sea en la emergencia hospitalaria o prehospitalaria, simultáneamente con la evaluación diagnóstica ${ }^{(14)}$.

Clásicamente se ha visto a la ICA como un evento homogéneo caracterizado por disfunción sistólica, bajo gasto cardíaco y sobrecarga de volumen. Este modelo conceptual y su tratamiento asociado se han aplicado a "todos los grupos" de pacientes. Por tanto, el tratamiento con diuréticos dirigido a aliviar la congestión se adoptó sin estudios clínicos que evaluaran su seguridad y eficacia a largo plazo. Datos surgidos de los registros de IC han desafiado este modelo tradicional revelando un "espectro" de entidades fisiopatológicas más complejo.

Siguiendo a Gheorghiade y colaboradores pueden distinguirse cuatro niveles de tratamiento(1):

- Medidas inmediatas en la emergencia o terapia intensiva.

- Medidas a mediano plazo, hospitalarias en cuidados moderados.

- Medidas a instalar prealta.

- Medidas de cuidado posalta para evitar el reingreso hospitalario y la mortalidad precoz.

\subsection{Medidas inmediatas en la emergencia o terapia intensiva}

Las metas en esta etapa deben ser:

- Tratar los síntomas, siendo lo prioritario la mejoría de la disnea y la oxigenación, así como su mecanismo responsable.

- Establecer el diagnóstico y perfil clínico.

- Mejorar la hemodinamia y la perfusión orgánica.

- Tratar las condiciones de riesgo vital.

- Identificar e iniciar el tratamiento de los factores precipitantes.

- Limitar el daño orgánico, sobre todo el miocárdico y renal.

- Prevenir el tromboembolismo (tromboprofilaxis).

- Minimizar la estadía en el área de cuidados críticos.

Hay evidencia actual de que el tratamiento temprano puede influenciar positivamente en el pronóstico clínico ${ }^{(2)}$.

Deben monitorizarse signos vitales: oximetría del pulso, PA, frecuencia y ritmo cardíaco, gasto urinario y monitoreo ECG continuo.

Identificados los pacientes con distrés respiratorio o compromiso hemodinámico severo deben trasladarse a unidades coronarias o intensivas donde se cuente con apoyo hemodinámico y posibilidades de asistencia respiratoria mecánica (ARM).

El inicio de altas dosis de nitratos intravenosos (i/v) en forma inmediata en los casos con edema pulmonar cardiogénico reduce la tasa de pacientes con ICA que requieren ventilación mecánica y reduce los puntos finales adversos ${ }^{(40)}$.

El inicio temprano de ventilación no invasiva (VNI) mejora la disnea y distrés respiratorio ${ }^{(41)}$.

En el registro ADHERE el inicio temprano $(\leq 6$ horas) comparado con el tardío (7-48 horas) de tratamiento vasodilatador estuvo asociado con tasas de mortalidad significativamente más bajas en pacientes internados con $\mathrm{ICA}^{(42)}$. 


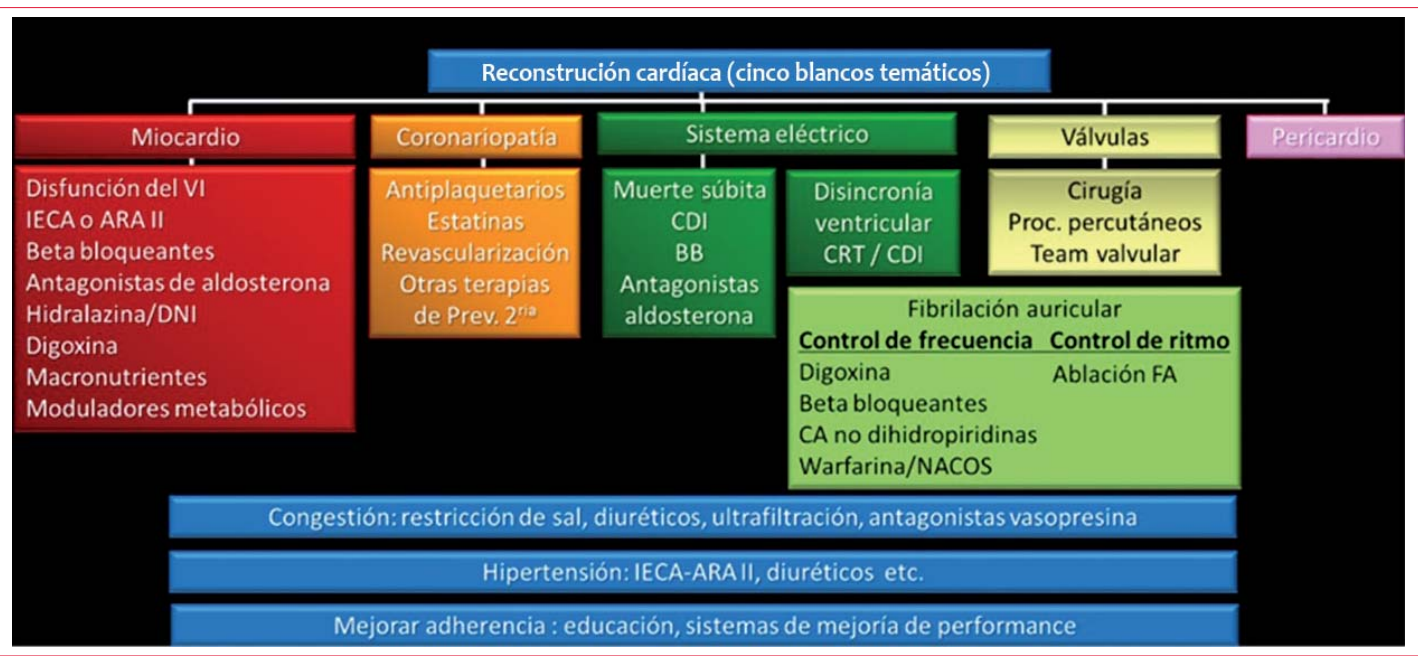

Figura 6. Los cinco "blancos temáticos" para manejar la IC.

VI: ventrículo izquierdo; IECA/ARA II: inhibidores de la enzima convertidora de angiotensina/ antagonistas de receptores II de la angiotensina; CDI: cardiodesfibrilador implantable; BB: betabloqueantes; CTR: terapia de resincronización; CA: calcioantagonistas; NACOS: nuevos anticoagulantes orales.

Además, el tratamiento inmediato de la ICA en la emergencia puede generar protección de órgano blanco. Como ya se mencionó, los niveles de troponinas como indicadores de injuria miocítica se incrementan temprano durante la descompensación en la ICA. La liberación de biomarcadores de daño orgánico están asociados con peor pronóstico y sugieren que el tratamiento temprano puede ser beneficioso en modular el proceso fisiopatológico minimizando el daño orgánico y la disfunción ${ }^{(3,43)}$.

El mismo concepto de tratamiento temprano también aplica a los desencadenantes:

- Neumonía.

- Sepsis.

- Emergencias hipertensivas.

- Taquiarritmias, bradiarritmias o trastornos de la conducción.

- Causas mecánicas de ICA: complicaciones mecánicas de los SCA (ruptura de pared libre, comunicación interventricular [CIV], insuficiencia mitral aguda); trauma de tórax; disfunción protésica o valvular nativa por endocarditis; disección aórtica o trombosis; causas raras de obstrucción como el mixoma.

- Embolia pulmonar.

En todos estos casos el diagnóstico ecocardiográfico resulta fundamental.

El esquema modificado de Gheorghiade y colaboradores agrupa en cinco capítulos los blancos temáticos que deben recordarse para el manejo global de la IC ${ }^{(44)}$ (figura 6).
9.1.1. Ingreso a terapia intensiva o unidad de cuidados coronarios

Los pacientes con disnea persistente o significativa o inestabilidad hemodinámica, o ambas, deben ser evaluados en un área con capacidad de reanimación inmediata como la UCI o la unidad coronaria (UC).

Los criterios de ingreso a UCI incluyen:

- Necesidad de intubación orotraqueal y ARM.

- Signos o síntomas de hipoperfusión.

- Saturación de oxígeno $\left(\mathrm{SpO}_{2}\right) \leq 90 \%$ (a pesar de aporte de $\mathrm{O}_{2}$ ).

- Uso de músculos accesorios de la respiración, frecuencia respiratoria $\geq 25 / \mathrm{min}$.

- Frecuencia cardíaca $\leq 40$ o $\geq 130 \mathrm{cpm}$, o PAS $\leq 90$ $\mathrm{mmHg}$.

Los pacientes sin estos signos de severidad pueden ingresar a sala común.

\subsubsection{Oxigenoterapia y soporte ventilatorio}

No debe usarse oxígeno suplementario en pacientes no hipoxémicos, pues causa vasoconstricción y reducción del gasto cardíaco. En el EPOC la hiperoxia puede incrementar el mismatch ventilación/perfusión, suprimiendo la ventilación y ocasionando hipercapnia.

La VNI mediante CPAP-BiPAP permite un soporte ventilatorio que mejora la ventilación/minuto y es especialmente útil en pacientes con hipercapnia (EPOC). La congestión pulmonar afecta la función pulmonar e incrementa el shunt intrapulmonar, causando hipoxemia. $\mathrm{La} \mathrm{FiO}_{2}$ debe aumentarse aún hasta $100 \%$ si es necesario, según la saturación de $\mathrm{O}_{2}$, pero debe evitarse la hiperoxia ${ }^{(4)}$. 
La VNI reduce el trabajo respiratorio y puede disminuir la tasa de intubación y tasa de mortalidad, si bien los datos respecto a la mortalidad son menos concluyentes.

Una revisión sistemática de 32 estudios (2.916 pacientes) comparando VNI con tratamiento estándar encontró que la VNI redujo significativamente la mortalidad hospitalaria y la intubación orotraqueal. Redujo la estadía en UCI (un día) sin diferencias en la estadía hospitalaria total. No ocurrió aumento significativo en la incidencia de IAM comparado con el tratamiento estándar ${ }^{(45)}$.

La revisión concluye que la VNI es efectiva y segura para el tratamiento de los pacientes con edema pulmonar agudo cardiogénico, pero la evidencia sobre el beneficio para reducir la mortalidad deriva de trabajos pequeños y se necesitan estudios mayores para asegurarlo.

Se recomienda generalmente el uso de VNI en los pacientes con ICA que tienen una frecuencia respiratoria $>20 \mathrm{resp} / \mathrm{min}$ y edema pulmonar $\mathrm{sin}$ shock.

Los factores que se asocian al éxito en el uso de VNI son:

- Sincronía paciente-respirador adecuada.

- Puntuación en la escala de Glasgow $>9$.

- Aceptación de la técnica por el paciente.

- Poca cantidad de secreciones.

- Puntuación de score APACHE II <21.

- Hipercapnia.

- $\mathrm{pH}$ arterial inicial $>7,1$.

- Respuesta adecuada en la primera hora de tratamiento.

- Presión arterial basal elevada.

9.1.3. Tratamiento farmacológico

9.1.3.1. Diuréticos

Los diuréticos son la base del tratamiento de la ICA con sobrecarga de volumen y congestión (90\% de ingresos por ICA). Aumentan la excreción renal de sal y agua y tienen cierto efecto vasodilatador. No deben indicarse en pacientes con ICA e hipoperfusión antes de lograr una perfusión adecuada.

El abordaje inicial de la congestión incluye diuréticos i/v con la adición de vasodilatadores para aliviar la disnea si la PA lo permite. Para potenciar la diuresis o superar la resistencia a los diuréticos se describe el bloqueo dual de la nefrona con diuréticos de asa (furosemide) más diuréticos tiazídicos o dosis natriuréticas de antagonistas de aldosterona ${ }^{(46,47)}$.

Dada la mayor biodisponibilidad de los diuréti$\cos \mathrm{i} / \mathrm{v}$ respecto a la vía oral (v/o) se recomienda la vía i/v para los pacientes con ICA, lo que logra inducir diuresis en 30-60 minutos posadministración.
De manera similar a lo que ocurre con la morfina, los diuréticos de asa i/v tienen un efecto venodilatador inicial que reduce la congestión pulmonar antes del inicio de la diuresis. La dosis inicial se elige generalmente de forma empírica, pero se recomienda que iguale o supere la dosis de mantenimiento diaria.

Respecto a las dosis y vías para el tratamiento diurético pueden extraerse conclusiones del estudio DOSE (Diuretic Optimization Strategies Evaluation) ${ }^{(48)}$.

Dicho estudio incluyó a 308 pacientes con ICA asignados a furosemide dosis bajas o dosis altas (2,5 veces la habitual) y administración en bolo i/v cada 12 horas o por infusión continua.

Los dos puntos finales principales fueron: a) De eficacia: evaluación global de los síntomas por el paciente; b) De seguridad: cambios en la creatininemia desde el inicio hasta 72 horas.

Los puntos finales secundarios fueron: disnea, cambios de peso, pérdida neta de líquidos, proporción de pacientes sin congestión a 72 horas, peoría de la función renal (creatininemia $>0,3 \mathrm{mg} / \mathrm{dl}$ ) hasta 72 horas, peoría o persistencia de IC, fracaso del tratamiento, cambios en biomarcadores a 72 horas, día 7 o alta y día 60 .

El estudio no encontró diferencias significativas en los síntomas ni en cambios en la función renal cuando se administró el tratamiento con diuréticos en bolo o en infusión continua, así como tampoco con dosis bajas o altas. Hubo una tendencia a mayor alivio sintomático en el grupo de dosis alta, con mejora de la reducción de volumen y disminución del peso a 72 horas. En el grupo asignado a dosis alta, la creatininemia aumentó, pero sin influir en la duración de la internación ni en la supervivencia.

Por tanto, el uso de diuréticos puede realizarse con cualquiera de las estrategias del estudio DOSE, aunque la infusión continua y dosis elevadas logran una más rápida mejoría sintomática y descongestión sin el riesgo de causar deterioro de la función renal que influya en el pronóstico.

\subsubsection{Fármacos vasodilatadores}

Los vasodilatadores son la segunda droga más usada en ICA luego de los diuréticos, pero no hay evidencia firme sobre sus efectos beneficiosos. Reducen el tono venoso (precarga), el tono arterial (poscarga), o ambas, con lo que disminuye la presión de llenado del VI, aumentan el volumen de eyección sistólico y mejoran el aporte periférico de oxígeno.

Son especialmente útiles en pacientes con ICA hipertensiva para mejorar los síntomas y reducir la congestión. Deben evitarse cuando la PAS $\leq 90$ mmHg o existe hipotensión sintomática. Las dosis 
deben controlarse cuidadosamente para evitar la hipotensión, la cual está relacionada con peor pronóstico.

Un análisis del registro ADHERE puso de manifiesto que los pacientes portadores de ICA tratados con fármacos vasodilatadores tras el ingreso hospitalario presentan una mortalidad significativamente inferior y estadías en UCI y hospitalaria total más cortas que los tratados con drogas inotrópicas positivas (dobutamina o milrinona) ${ }^{(49)}$, indicando que los vasodilatadores deberían preferirse sobre los inotrópicos.

El vasodilatador utilizado frecuentemente en nuestro medio es la nitroglicerina, menos frecuentemente el nitroprusiato (en la ICA hipertensiva) y no se dispone de nesiritide.

Nesiritide es la forma recombinante del BNP. Aumenta la dilatación arterial y venosa incrementando la concentración intracelular de monofosfato cíclico de guanosina (GMPc), actúa disminuyendo las presiones intracavitarias, disminuye la PCP, la resistencia vascular pulmonar y aumenta el gasto cardíaco.

A pesar de un inicial entusiasmo por su utilización los estudios no han demostrado beneficios en los puntos finales. El estudio ASCEND-HF no logró demostrar que el uso de nesiritide en pacientes con ICA modificara los puntos finales de mortalidad a 30 días, reingreso por IC, o el combinado de mortalidad a 30 días más reingreso por IC en pacientes tratados con nesiritide versus placebo dentro de las 24 horas del ingreso hospitalario, pese a lograr una leve pero no significativa mejoría de la disnea a 6 y 24 horas en el grupo nesiritide ${ }^{(50)}$.

\subsubsection{Fármacos inotrópicos positivos}

El uso de los fármacos con acción inotrópica positiva debe reservarse para los pacientes con reducciones severas del gasto cardíaco que comprometan la perfusión de órganos vitales, lo que ocurre sobre todo en la ICA hipotensiva (PAS $\leq 90 \mathrm{mmHg}$ ), que constituye un grupo pequeño en torno a 5\%-10\% de las ICA. No se recomienda el uso de inotrópicos cuando existe hipotensión si hay factores corregibles como arritmias o hipovolemia.

Los inotrópicos positivos, especialmente los catecolamínicos (dopamina, dobutamina) mejoran la contractilidad miocárdica a través del aumento del calcio intracelular. Esto está asociado a la aparición de efectos colaterales como el aumento del riesgo de arritmias cardíacas, aumento de las demandas de oxígeno y, por tanto, de la posibilidad de inducir isquemia miocárdica. Por ello, hay precauciones sobre su uso, sobre todo en forma prolongada ya que podrían aumentar la mortalidad.
La milrinona, un inhibidor de la fosfodiesterasa III, es un inotrópico no catecolamínico que produce efecto inotrópico positivo y vasodilatador independiente de la estimulación del receptor $\beta$ adrenérgico. Actúa en el corazón por la misma vía de traducción de señal que la dobutamina, incrementando el AMP cíclico intracelular y aumentando el calcio intracelular. Por esto comparte las desventajas referidas para las catecolaminas y agrega mayor efecto vasodilatador pudiendo causar hipotensión. Por tanto, el "costo" clínico de esta terapia inotrópica positiva en la ICA puede manifestarse en eventos adversos de riesgo vital.

El uso hospitalario de milrinona se asoció con una tendencia hacia mayor mortalidad a 60 días. Se ha reportado una relación significativa entre etiología de la IC y pronóstico. Pacientes con etiología isquémica tratados con milrinona tuvieron mayor mortalidad a 60 días $(11,6 \%)$ respecto al grupo no isquémico $(7,5 \% \mathrm{p}=0,03)$ y mayor tasa compuesta de mortalidad y rehospitalización $(42 \%$ vs $35 \%$ $\mathrm{p}=0,01$ ). Puede concluirse que la milrinona no debe usarse "rutinariamente" en pacientes con exacerbaciones de $\mathrm{IC}^{(51)}$.

Levosimendán es un nuevo agente inotrópico sensibilizador del calcio que incrementa la contractilidad sin elevar el AMP cíclico intracelular; aumenta la afinidad de la troponina $\mathrm{C}$ por el calcio sin elevar la concentración intracelular del mismo. Es preferible sobre la dobutamina para revertir el efecto del betabloqueo si se piensa que este contribuye a la hipoperfusión. No causa vasoconstricción, ya que no aumenta las concentraciones de adrenalina o noradrenalina y mejora el gasto cardíaco y el volumen de eyección. Es un vasodilatador y por tanto no es utilizable en pacientes hipotensos o en SC, a no ser que se combine con otros inotrópicos o vasopreso$\operatorname{res}^{(52)}$.

En nuestro medio está disponible pero su uso se restringe a algunos pacientes especiales y a centros terciarios de asistencia cardiológica, por otra parte su elevado costo limita el uso generalizado.

Se infunde durante un total de 24 horas, pero sus efectos farmacológicos beneficiosos persisten en el tiempo más allá del cese de la infusión.

\subsubsection{Fármacos vasopresores}

Los vasopresores son drogas con efectos vasoconstrictores periféricos prominentes. Este efecto se logra con fármacos catecolaminérgicos como la noradrenalina o la dopamina en altas dosis: 5 $\mathrm{mg} / \mathrm{kg} / \mathrm{min}$. Son utilizadas en pacientes con hipotensión marcada en los que se busca aumentar la PA y redistribuir el flujo sanguíneo hacia los órganos vitales. Esto se obtiene a expensas de un in- 
cremento de la poscarga del VI. Se ha comparado el uso de la dopamina con la noradrenalina en varios pacientes con shock, y se ha sugerido que la noradrenalina podría tener menos efectos colaterales y menor mortalidad ${ }^{(53)}$.

El uso de adrenalina, el "prototipo" de catecolamina, debe limitarse a pacientes con hipotensión persistente a pesar de adecuadas presiones de llenado cavitario y adecuado uso de otros agentes vasoactivos previos.

9.1.3.5. Fármacos investigados

En los últimos años se han estudiado múltiples drogas "emergentes", que basándose en los diferentes mecanismos fisiopatológicos implicados en la ICA intentaron influir positivamente en su pronóstico.

Muchos de estos estudios presentaron resultados negativos en sus puntos finales:

- Antagonistas de vasopresina: tolvaptán (EVEREST).

- Antagonistas de adenosina A: rolofilina (PROTECT).

- Péptido natriurético renal: ularitide (True-HF).

- Activadores de miosina cardíaca: Omecamtiv mercabil (ATOMIC-AHF).

- Moduladores metabólicos: serelaxina (RELAXAHF).

- Estimulantes del SERCA2: istaroxima (inhibidor de la bomba Na-K ATP y estimulante de la actividad de la isoforma 2 de calcio ATPasa del retículo sarcoplásmico).

Esta multiplicidad de estudios y drogas confirman las apreciaciones realizadas al inicio del capítulo indicando que pese a una intensa investigación en el área del tratamiento farmacológico de la ICA, han existido pocos avances aplicables al mundo real(54-59).

\subsubsection{Tratamientos no farmacológicos}

9.1.4.1. Ultrafiltración

La congestión causa el $90 \%$ de las internaciones por IC. Su gravedad y persistencia se asocian a peor evolución clínica, con relación directa entre los valores de presión capilar pulmonar y la mortalidad posterior al alta.

A mayor congestión, mayor activación neurohumoral del SRAA, alteración microvascular intrarrenal y estrés oxidativo. La filtración glomerular está disminuida, la reabsorción de sodio aumentada y la excreción de sodio urinaria reducida.

El aumento de la presión venosa central se asocia, de manera independiente, al deterioro de la función renal y a la evolución clínica desfavorable.
Los diuréticos de asa son el tratamiento de primera línea en la ICA, pero la resistencia a los diuréticos y el deterioro de la función renal son hechos relevantes. Aproximadamente 40\% de los pacientes internados por IC se van de alta con congestión no resuelta y esto causa aumento en la tasa de reingreso y en la mortalidad.

La ultrafiltración (UF) veno-venosa periférica ha surgido como un tratamiento complementario a los diuréticos en la ICA con congestión sistémica o pulmonar, o ambas.

Elimina sodio y agua a través de una membrana semipermeable en respuesta a un gradiente transmembrana creado por la diferencia de presión hidrostática ${ }^{(60)}$.

Los solutos de un tamaño molecular inferior al de los poros de la membrana, como iones y urea, contenidos en la cantidad de agua filtrada del plasma, se extraen a la misma concentración que el agua del plasma; no corrige las alteraciones iónicas y metabólicas significativas ni moléculas de alto peso molecular (citoquinas y depresores miocárdicos) sin una hemodiálisis asociada por las características propias de la membrana utilizada.

El producto de la UF es isotónico, mientras que la diuresis producida por diuréticos de asa es hipotónica, lo cual reduce al mínimo las anomalías electrolíticas y la activación neurohumoral.

La UF elimina más sodio y menos potasio que los diuréticos para una pérdida de volumen equivalente y contribuye a la mejoría clínica a corto plazo en pacientes con ICA congestiva por varias vías relacionadas con la interacción corazón-pulmones: a) Acción mecánica directa corrigiendo la sobrecarga hídrica, reduciendo la presión auricular derecha, arterial pulmonar, las resistencias vasculares periféricas y las presiones de llenado ventricular. b) Reducción del edema miocárdico, mejora de la función diastólica y rendimiento cardíaco global. c) Corrección del desequilibrio neurohumoral y de la hipovolemia relativa inducida por la IC y el tratamiento diurético. d) Reducción del agua extravascular pulmonar, el shunt y el espacio muerto, con mejora del intercambio gaseoso.

Pese a estas premisas fisiopatológicas se desconoce la oportunidad y el momento en el cual los pacientes con ICA se benefician más con la UF.

Un factor importante a definir es la "tasa" de UF, puesto que una extracción de volumen muy rápida, que supere la tasa de rellenado del plasma, puede conducir a depleción de volumen intravascular, hipotensión e hipoperfusión renal.

La UF puede aplicarse en forma segura a pacientes congestivos, cualquiera sea su FEVI ${ }^{(60)}$. 
La evidencia indica que la UF mejora la congestión pulmonar y periférica, la función pulmonar y la hemodinamia sin causar efectos adversos sobre la función renal.

Los cambios hemodinámicos favorables observados con UF pueden deberse a la mejora de la función renal y al restablecimiento de la capacidad de respuesta a los diuréticos.

El estudio UNLOAD incluyó a 200 pacientes con ICA asignados a UF o diuréticos de asa en las 24 horas siguientes al ingreso. El grupo UF mostró mayor pérdida de peso y disminución en las rehospitalizaciones por IC, sin diferencias en la percepción de disnea y con una tendencia a la peoría de la función renal respecto al grupo de tratamiento diurético ${ }^{(61)}$.

El estudio Cardiorenal Rescue Study in Acute Decompensated Heart Failure (CARRESS-HF) incluyó a pacientes con SCR y congestión persistente, randomizados, para recibir un tratamiento farmacológico basado en un algoritmo o UF como tratamiento de rescate. Los pacientes del grupo UF no mostraron mayor pérdida de peso y presentaron aumento significativo de creatininemia y mayor tasa de eventos adversos, como sepsis ${ }^{(62)}$.

Estos resultados plantean dudas sobre el papel de la UF para tratar la resistencia a diuréticos, disfunción renal y SCR. La seguridad y eficacia de la UF dependen de la capacidad de eliminar líquido sin causar inestabilidad hemodinámica o deterioro de la función renal. Esto se aplica especialmente a los pacientes con ICA a predominio derecho e ICFEp, que son propensos a la depleción de volumen intravascular. Aparte de estas complicaciones también genera problemas comunes a cualquier técnica de tratamiento sustitutivo renal basada en circulación extracorpórea, siendo los más frecuentes los ligados al catéter (por ejemplo, infección del acceso venoso) y la coagulación del circuito $^{(60)}$.

\subsubsection{Asistencia circulatoria mecánica}

La ICA incluye un amplio espectro de trastornos incluido el SC.

Este constituye un estado de hipoperfusión de órganos blanco causado por la disfunción ventricular, asociado a mal pronóstico global y a una alta mortalidad que ronda el $50 \%$ según las series.

Existen numerosas causas de SC, pero el IAM con fallo ventricular izquierdo es la más frecuente. El fundamento del uso de asistencia circulatoria mecánica (ACM) es restablecer una presión de perfusión suficiente para evitar las disfunciones orgánicas y así ganar tiempo para permitir la recuperación ventricular.
Las indicaciones de ACM en la ICA más frecuentes $\operatorname{son}^{(60)}$ :

- SC pos IAM.

- Miocarditis fulminante.

- IC crónica descompensada refractaria al tratamiento inotrópico.

- Incapacidad de salida de CEC poscirugía cardíaca.

- Fallo del injerto postrasplante cardíaco.

- Estado posparo cardíaco.

En estos contextos, el papel de la ACM puede ser uno de los siguientes:

- Tratamiento puente para trasplante.

- Tratamiento de destino: alternativa en pacientes en quienes se contraindica el trasplante de corazón.

- Tratamiento puente para la recuperación.

- Tratamiento puente para puente: en los pacientes que presentan un shock grave o después de paro cardíaco que reciben apoyo con un dispositivo temporal para evaluar si serán candidatos a apoyo a largo plazo.

- Tratamiento puente para la decisión: utilizado cuando no está claro cuál es la mejor opción para un determinado paciente en el momento de implantar el dispositivo.

Los dispositivos existentes para ACM son:

- Balón de contrapulsación intraórtico (BIAC).

- Dispositivo Impella.

- Oxigenadores de membrana extracorpórea: ECMO.

- Dispositivos de asistencia ventricular: DAV (por ejemplo, Heart Mate).

En nuestro medio solo se dispone de BIAC y su uso se restringe a centros terciarios con acceso inmediato a cirugía cardíaca y hemodinamia, por lo cual no se abordará este punto. Recientemente se ha agregado al arsenal terapéutico la presencia de ECMO.

Sin embargo, es pertinente mencionar los resultados del estudio SHOCK II, que no mostraron beneficios en mortalidad ni en puntos secundarios con el uso de BIAC en el paciente con IAM complicado con SC. Por tal motivo las guías de IAM con elevación de ST colocan el uso de BIAC para el IAM complicado con SC como indicación IIb B en vez de indicación clase I como en guías previas ${ }^{(63)}$.

\subsection{Medidas a mediano plazo, estadía hospitalaria en cuidados moderados}

Las metas en esta etapa son:

- Monitorizar y revalorar la situación clínica. 
- Valorar las presiones del VI y VD.

- Valorar y tratar las condiciones extracardíacas y las comorbilidades.

- Estabilizar al paciente y optimizar la estrategia terapéutica.

- Iniciar y titular la terapia farmacológica.

- Identificar la etiología y valorar la viabilidad miocárdica.

- En el paciente seleccionado considerar la terapia con dispositivos.

En esta etapa, una vez controlada la situación de riesgo vital, se debe continuar el monitoreo clínico y paraclínico inicial, ajustar las dosis de las drogas realizando el "cambio" hacia drogas orales a las dosis máximas toleradas y que en los estudios de IC han mostrado ser efectivas para mejorar el pronóstico a mediano y largo plazo(1,7).

Se debe ajustar el tratamiento de las comorbilidades y de los factores de descompensación; es el momento de confirmar el diagnóstico etiológico realizando los estudios complementarios que sean necesarios (coronariografía, test de isquemia o viabilidad miocárdica, o ambos, cardiorresonancia).

También es momento para plantear la terapia con dispositivos como resincronización ventricular y cardiodesfibrilador en pacientes seleccionados ${ }^{(64)}$.

\subsection{Medidas a instalar prealta}

Constituye una etapa fundamental muchas veces minimizada.

Se debe establecer el plan y la estrategia de seguimiento posalta, considerando los siguientes puntos:

- Enrolar al paciente en un programa educativo sobre el manejo de la enfermedad.

- Asegurarse que sea asistido por el médico general dentro de la semana posalta.

- Programar la consulta con el equipo cardiológico dentro de dos semanas posalta.

- Planificar, titular y optimizar las drogas modificadoras de la enfermedad (betabloqueantes, IECA, antialdosterónicos, entre otros).

- Asegurar que se haga la valoración para terapia con dispositivos.

- Prevenir el reingreso hospitalario temprano.

\subsection{Medidas de cuidado posalta}

Luego del alta se ha definido un "período vulnerable" que se presenta dentro de los 60-90 días. Durante el mismo ocurren reingresos y muertes en una significativa proporción de pacientes ${ }^{(1,65)}$.

Los condicionantes principales de este período son: el deterioro clínico en los signos y síntomas, el perfil neurohormonal presente y la función renal
Resumen conceptual

- La ICA es una entidad con alta prevalencia y es la causa de hospitalización más común en pacientes añosos.

- Se define como el cambio gradual o rápido de síntomas y signos de IC que resultan en la necesidad de tratamiento urgente.

- Se recomienda un abordaje conceptual similar al del síndrome coronario agudo: "Cuanto más pronto mejor".

- Existen tres presentaciones clínicas: a) IC "de novo"; b) agudización de una IC previa. C) IC avanzada.

- Se recomienda la evaluación clínica basada en el examen del paciente para detectar la presencia (húmedo) o la ausencia (seco) de síntomas o signos de congestión y la presencia (frío) o la ausencia (caliente) de signos de hipoperfusión periférica.

- El proceso diagnóstico debe asegurar que la ICA es la causa de la disnea; identificar la enfermedad cardíaca subyacente y los factores precipitantes.

- Se deben considerar cuatro niveles de tratamiento: a) medidas inmediatas en la emergencia o terapia intensiva; b) medidas a mediano plazo, hospitalarias en cuidados moderados; c) medidas a instalar prealta; d) medidas de cuidado posalta para evitar el reingreso hospitalario y la mortalidad precoz.

durante las primeras semanas posalta. El deterioro puede ocurrir a pesar de que se realice tratamiento estándar.

Se recomienda especial atención en este período vulnerable mediante un adecuado control, visitas programadas, desarrollo de programas de seguimiento telefónico o domiciliario en conjunto con valoración clínica: peso y diuresis, y paraclínica: función renal, medio interno y PN.

Todas estas estrategias van dirigidas a detectar precozmente signos de descompensación, de disfunción orgánica y complicaciones generadas por la terapéutica como las disionías y la injuria renal aguda, que corregidas a tiempo eviten el reingreso y la mortalidad asociada.

La ICA es una de las entidades en las que más se aplica la necesidad de constituir un equipo de trabajo o Heart team ${ }^{(14)}$.

Allí, junto al cardiólogo clínico, confluye un verdadero equipo multidisciplinario con el médico de emergencia, generalista, internista, intensivista, imagenólogo, nefrólogo, enfermero universita- 
rio, fisiatra, nutricionista y asistente social, entre otros. La acción de este equipo es capaz de generar un resultado final más eficiente y con mejores resultados que cada una de las partes actuando individualmente.

Esta es la recomendación actual y la tendencia hacia la que se deberá evolucionar en nuestro medio para mejorar la asistencia de este desafiante y complejo grupo de pacientes.

Para concluir es bueno recordar, aunque modificados, los conceptos de uno de los líderes de opinión en la materia, el Dr. Alexandre Mebazaa, que resumen muy bien el manejo actual del síndrome:

"Debemos pensar la estrategia correcta para 'nuestro' paciente, pero 'iniciarla tan pronto sea posible', debemos seguir al paciente de cercay 'monitorizarlo' con los elementos 'clínicos y paraclínicos' adecuados, estando atentos para 'revalorar el cuadro clínico' $y$ 'cambiar de estrategia' rápidamente si fuera necesario, actuando siempre en modalidad de 'equipo del corazón'”.

\section{Bibliografía}

1. Gheorghiade M, Pang PS. Acute Heart Failure Syndromes. J Am Coll Cardiol 2009; 53(7):557-73.

2. Mebazaa A, Yilmaz MB, Levy P, Ponikowski P, Peacock WF, Laribi S, et al. Recommendations on pre-hospital and early hospital management of acute heart failure: a consensus paper from the Heart Failure Association of the European Society of Cardiology, the European Society of Emergency Medicine and the Society of Academic Emergency Medicine-short version. Eur Heart J 2015; 36(30):1 958-66.

3. Metra M, Cotter G, Davison BA, Felker GM, Filippatos G, Greenberg BH, et al. Effect of serelaxin on cardiac, renal, and hepatic biomarkers in the Relaxin in Acute Heart Failure (RELAX-AHF) development program: correlation with outcomes. J Am Coll Cardiol 2013; 61(2):196-206.

4. Ponikowski P, Voors A, Anker S, Bueno H, Cleland JG, Coats AJ, et al. 2016 ESC guidelines for the diagnosis and treatment of acute and chronic heart failure: The Task Force for the diagnosis and treatment of acute and chronic heart failure of the European Society of Cardiology (ESC). Eur Heart J 2016; 37(27):2129-200.

5. Maggioni A, Dahlstrom U, Filippatos G, Chioncel O, Leiro MC, Drozdz J, et al. EURObservational Research Programme: TheHeart Failure Pilot Survey (ESC-HF Pilot). Eur J Heart Fail 2010; 12(10):1076-84.

6. Gheorghiade M, Zannad F, Sopko G, Klein L, Piña IL, Konstam MA, et al. The International Working Group on Acute Heart Failure Syndromes.
Current State and Framework for Future Research. Circulation 2005; 112(25):3958-68.

7. Mc Murray J, Adamopoulos S, Anker S, Auricchio A, Bohm M, Dickstein K, et al. The Task Force for the Diagnosis and Treatment of Acute and Chronic Heart Failure 2012 of the European Society of Cardiology. Developed in collaboration with the Heart Failure Association (HFA) of the ESC. Eur J Heart Fail 2012; 14(8):803-69.

8. Zannad F, Adamopoulos C, Mebazaa A, Gheorghiade M. The challenge of acute decompensated heart failure. Heart Fail Rev 2006; 11(2):135-9.

9. Stevenson L. Tailored therapy to hemodynamic goals for advanced heart failure. Eur J Heart Fail 1999; 1(3):251-7.

10. Nohria A, Tsang S, Fang J, Lewis EF, Jarcho JA, Mudge GH, et al. Clinical assessment identifies hemodynamic profiles that predict outcomes in patients admitted with heart failure. J Am Coll Cardiol 2003; 41(10):1797-804.

11. Weintraub NL, Collins SP, Pang PS, Levy PD, Anderson AS, Arslanian-Engoren C, et al. Acute heart failure syndromes: emergency department presentation, treatment, and disposition: current approaches and future aims: a scientific statement from the American Heart Association. Circulation 2010; 122(19):1975-96.

12. Gheorghiade M, Abraham WT, Albert NM, Greenberg BH, O'Connor CM, She L, et al. OPTIMIZE-HF Investigators and Coordinators. Systolic blood pressure at admission, clinical characteristics, and outcomes in patients hospitalized with acute heart failure. JAMA 2006; 296(18):2217-26.

13. Doshi D, Ben-Yehuda O, Bonafede M, Bonafede M, Josephy N, Karmpaliotis D, et al. Underutilization of coronary artery disease testing among patients hospitalized with new-onset heart failure. J Am Coll Cardiol 2016; 68(5):450-8.

14. Mueller C, Christ M, Cowie M, Cullen L, Maisel AS, Masip J, et al. European Society of Cardiology-Acute Cardiovascular Care Association position paper on acute heart failure: a call for interdisciplinary care. Eur Heart J Acute Cardiovasc Care 2017; 6(1):81-6.

15. Nieminen MS, Brutsaert D, Dickstein K, Drexler H, Follath F, Harjola VP, et al. EuroHeart Failure Survey II (EHFS II): a survey on hospitalized acute heart failure patients: description of population. Eur Heart J 2006; 27(22):2725-36.

16. Fonarow GC, Abraham WT, Albert NM, Stough WG, Gheorghiade M, Greenberg BH, et al. Factors identified as precipitating hospital admissions for heart failure and clinical outcomes: findings from OPTIMIZE-HF. Arch Intern Med 2008; 168(8): 847-54. 
17. Lancellotti P, Price S, Edvardsen T, Cosyns B, Neskovic AN, Dulgheru R, et al. The use of echocardiography in acute cardiovascular care: recommendations of the European Association of Cardiovascular Imaging and the Acute Cardiovascular Care Association. Eur Heart J Cardiovasc Imaging 2015; 16(2):119-46.

18. Maisel A. Natriuretic peptide-guided therapy for heart failure: ready for "battle" or too "scarred" by the challenges of trial design? J Am Coll Cardiol $2009 ; 55(1): 61-4$

19. Kazanegra R, Cheng V, Garcia A, Krishnaswamy $P$, Gardetto $\mathbf{N}$, Clopton $P$, et al. A rapid test for B-type natriuretic peptide correlates with falling wedge pressures in patients treated for decompensated heart failure: a pilot study. J Card Fail $2001 ; 7(1): 21-9$

20. Ray $\mathbf{P}$, Birolleau S, Lefort $\mathbf{Y}$, Becquemin $\mathbf{M H}$, Beigelman C, Isnard R, et al. Acute respiratory failure in the elderly: etiology, emergency diagnosis and prognosis. Crit Care 2006; 10(3):R82.

21. Maisel A, Krishnaswamy P, Nowak R, McCord J, Hollander JE, Duc P, et al. Rapid measurement of B-type natriuretic peptide in the emergency diagnosis of heart failure. N Engl J Med 2002; 347(3): 161-7.

22. Maisel A, Hollander JE, Guss D, McCullough $P$, Nowak R, Green G, et al. Primary results of the Rapid Emergency Department Heart Failure Outpatient Trial (REDHOT): a multicenter study of B-type natriuretic peptide levels, emergency department decision making, and outcomes in patients presenting with shortness of breath. J Am Coll Cardiol 2004 44(6):1328-33.

23. Abraham W, Adams K, Fonarow G, Costanzo MR, Berkowitz RL, LeJemtel TH, et al. ADHERE Scientific Advisory Committee and Investigators; ADHERE Study Group. In-hospital mortality in patients with acute decompensated heart failure requiring intravenous vasoactive medications: an analysis from the Acute Decompensated Heart Failure National Registry (ADHERE). J Am Coll Cardiol 2005; 46(1):57-64.

24. Boyer B, Hart K, Sperling M, Lindsell CJ, Collins SP. Biomarker Changes During Acute Heart Failure Treatment. Congest Heart Fail 2012; 18(2):91-7.

25. Troughton RW, Frampton CM, Nicholls MG. Biomarker-guided treatment of heart failure: still waiting for a definitive answer. J Am Coll Cardiol $2010 ; 56(25): 2101-4$

26. Gaggin HK, Januzzi JL Jr. Biomarkers and diagnostics in heart failure. Biochim Biophys Acta 2013; 1832(12):2442-50.

27. Butler J, Gheorghiade M, Kelkar A, Fonarow GC, Anker S, Greene SJ, et al. In-hospital worse- ning heart failure. Eur J Heart Fail 2015; 17(11):1104-13.

28. Xue Y, Clopton P, Peacock W, Maisel AS. Serial changes in high-sensitive troponin I predict outcome in patients with decompensated heart failure. Eur J Heart Fail 2011; 13(1):37-42.

29. Damman K, Tang WH, Testani JM, McMurray J. Terminology and definition of changes renal function in heart failure. Eur Heart J 2014; 35(48): 3413-6.

30. Ronco C, McCullough P, Anker S, Anand I, Aspromonte N, Bagshaw SM, et al. Acute Dialysis Quality Initiative (ADQI) consensus group. Cardio-renal syndromes: report from the consensus conference of the acute dialysis quality initiative. Eur Heart J 2010; 31(6):703-11.

31. Lassus J, Harjola V. Cystatin C: a step forward in assessing kidney function and cardiovascular risk. Heart Fail Rev 2012; 17(2):251-61.

32. van Deursen V, Damman $\mathbf{K}$, Hillege $\mathbf{H}$, van Beek AP, van Veldhuisen DJ, Voors AA. Abnormal liver function in relation to hemodynamic profile in heart failure patients. J Card Fail 2010; 16(1):84-90.

33. Chang C, Schiano T. Review article: drug hepatotoxicity. Aliment Pharmacol Ther 2007; 25(10): 1135-51.

34. Ambrosy A, Vaduganathan M, Huffman M, Khan S, Kwasny MJ, Fought AJ, et al. Clinical course and predictive value of liver function tests in patients hospitalized for worsening heart failure with reduced ejection fraction: an analysis of the EVEREST trial. Eur J Heart Fail 2012; 14(3): 302-11.

35. Fonarow G, Stough W, Abraham W, Albert NM, Gheorghiade M, Greenberg BH, et al. OPTIMIZE-HF Investigators and Hospitals. Characteristics, treatments, and outcomes of patients with preserved systolic function hospitalized for heart failure: a report from the OPTIMIZE-HF Registry. J Am Coll Cardiol 2007; 50(8):768-77.

36. Maggioni A, Dahlstrom U, Filippatos G, Chioncel O, Crespo Leiro $M$, Drozdz J, et al. EURObservational Research Programme: regional differences and 1-year follow-up results of the Heart Failure Pilot Survey (ESC-HF Pilot). Eur J Heart Fail 2013; 15(7):808-17.

37. Fonarow GC, Adams KF Jr, Abraham WT, Yancy CW, Boscardin WJ; ADHERE Scientific Advisory Committee, Study Group, and Investigators. Risk stratification for in-hospital mortality in acutely decompensated heart failure: classification and regression tree analysis. JAMA 2005; 293(5):572-80. 
38. Fonarow GC, Peacock WF, Phillips CO, Givertz MM, Lopatin M; ADHERE Scientific Advisory Committee and Investigators. Admission B-type natriuretic peptide levels and in-hospital mortality in acute decompensated heart failure. J Am Coll Cardiol 2007; 49(19):1943-50.

39. Diercks D, Peacock W, Kirk J, Weber JE. ED patients with heart failure: Identification of an observational unit appropriate cohort. Am J Emerg Med 2006; 24(3):319-24

40. Cotter G, Metzkor E, Kaluski E, Faigenberg Z, Miller R, Simovitz A, et al. Randomised trial of high-dose isosorbide dinitrate plus low-dose furosemide versus high-dose furosemide plus low-dose isosorbide dinitrate in severe pulmonary oedema. Lancet 1998; 351(9100):389-93.

41. Gray A, Goodacre S, Newby D, Masson M, Sampson F, Nicholl J. Noninvasive ventilation in acute cardiogenic pulmonary edema. N Engl J Med 2008; 359(2):142-51.

42. Peacock W, Emerman C, Costanzo M, Diercks DB, Lopatin M, Fonarow JC. Early vasoactive drugs improve heart failure outcomes. Congest Heart Fail 2009; 15(6):256-64.

43. Peacock W 4th, De Marco T, Fonarow G, Diercks D, Wynne J, Apple FS, et al. ADHERE investigators. Cardiac troponin and outcome in acute heart failure. N Engl J Med 2008; 358(20):2117-26.

44. Gheorghiade M, Vaduganathan M, Fonarow G, Bonow RO. Rehospitalization for Heart Failure Problems and Perspectives. J Am Coll Cardiol 2013; 61(4):391-403.

45. Vital F, Ladeira M, Atallah A. Non-invasive positive pressure ventilation (CPAP or bilevel NPPV) for cardiogenic pulmonary oedema. Cochrane Database Syst Rev 2013; 5:CD005351.

46. $\operatorname{Cox} Z$, Lenihan D. Loop diuretic resistance in heart failure: resistance etiologybased strategies to restoring diuretic efficacy. J Card Fail 2014; 20(8):611-22.

47. Mentz R, Kjeldsen K, Rossi G, Voors AA, Cleland JG, Anker SD, et al. Decongestion in acute heart failure. Eur J Heart Fail 2014; 16(5):471-82.

48. Felker G, Lee K, Bull D, Redfield MM, Stevenson LW, Goldsmith SM, et al. Diuretic strategies in patients with acute decompensated heart failure. N Engl J Med 2011; 364(9):797-805.

49. Peacock W, Fonarow G, Emerman C, Mills RM, Wynne J. ADHERE Scientific Advisory Committee and Investigators; Adhere Study Group. Impact of early initiation of intravenous therapy for acute decompensated heart failure on outcomes in ADHERE. Cardiology 2007; 107(1):44-51.

50. O'Connor C, Starling A, Hernandez AF, Armstrong PW, Dickstein K, Hasselblad V, et al. Effect of Nesiritide in Patients with Acute Decom- pensated Heart Failure. N Engl J Med 2011; 365(1): $32-43$.

51. Felker G, Benza R, Chandler A, Leimberger JD, Cuffe MS, Califf RM, et al. Heart failure etiology and response to milrinone in decompensated heart failure. Results from the OPTIME-CHF study. J Am Coll Cardiol 2003; 41(6):997-1003.

52. Packer M, Colucci W, Fisher L, Massie BM, Teerlink JR, Young J, et al. Effect of levosimendan on the short-term clinical course of patients with acutely decompensated heart failure. JACC Heart Fail 2013; 1(2):103-11.

53. De Backer D, Biston P, Devriendt J, Madl C, Chochrad D, Aldecoa C, et al. Comparison of dopamine and norepinephrine in the treatment of shock. N Engl J Med 2010; 362(9):779-89.

54. Konstam MA, Gheorghiade M, Burnett JC, Grinfeld L, Maggioni AP, Swedberg K, et al. Effects of oral Tolvaptan in patients hospitalized for worsening heart failure: the EVEREST Outcome Trial. JAMA 2007; 297(12):1319-31.

55. Massie B, O’Connor C, Metra M, Ponikowski P, Teerlink JR, Cotter G, et al. Rolofylline, an Adenosine A1 receptor antagonist, in acute heart failure. New Engl J Med 2010; 363(15):1419-28.

56. Mitrovic V, Luss H, Nitsche K, Frossmann K, Maronde E, Fricke K, et al. Effects of the renal natriuretic peptide urodilatin (ularitide) in patients with decompensated chronic heart failure: A double-blind, placebo-controlled, ascending-dose trial. Am Heart J 2005; 150(6):1239.

57. Teerlink J, Felker G, McMurray J, Ponikowski P, Metra M, Filippatos GS, et al. Acute treatment with omecamtiv mercabil to increase contractility in acute heart failure: the ATOMIC-AHF Study. J Am Coll Cardiol 2016 29; 67(12):1444-55.

58. Teerlink J, Cotter G, Davison B, Felker GM, Filippatos G, Greenberg BH, et al. Serelaxin, recombinant human relaxin-2, for treatment of acute heart failure (RELAX-AHF): a randomised, placebo-controlled trial. Lancet 2013; 381(9860):29-39.

59. Gheorghiade M, Blair JE, Filippatos GS, Macarie C, Ruzyllo W, Korewicki J, et al. Hemodynamic, echocardiographic, and neurohormonal effects of istaroxime, a novel intravenous inotropic and lusitropic agent: a randomized controlled trial in patients hospitalized with heart failure. J Am Coll Cardiol 2008; 51(23):2276-85

60. Placido R, Mebazaa A. Tratamiento no farmacológico de la insuficiencia cardiaca aguda. Rev Esp Cardiol 2015; 68(9):794-802.

61. Costanzo M, Guglin M, Saltzberg M, Jessup M, Bart BA, Teerlink JR, et al. Ultrafiltration versus intravenous diuretics for patients hospitalized for 
acute decompensated heart failure. J Am Coll Cardiol 2007; 49(10):675-83.

62. Bart BA, Goldsmith SR, Lee KL, Givertz MM, O'Connor CM, Bull DA, et al. Ultrafiltration in decompensated heart failure with cardiorenal syndrome. N Engl J Med 2012; 367(24):2296-304.

63. Thiele H, Zeymer U, Neumann FJ, Ferenc M, Olbrich HG, Hausleiter J, et al. Intraaortic balloon support for myocardial infarction with cardiogenic shock. N Engl J Med 2012; 367(14):1287-96.
64. Pang P, Komajda M, Gheorghiade M. The current and future management of acute heart failure syndromes. Eur Heart J 2010; 31(7):784-93.

65. Solomon SD, Dobson J, Pocock S, Skali H, McMurray JJ, Granger CB, et al. Influence of nonfatal hospitalization for heart failure on subsequent mortality in patients with chronic heart failure. Circulation 2007; 116(13):1482-7. 